\title{
Abstract zu: Peter Handkes Fiktionen der Leserschaft
}

Erschienen in: Unterstellte Leseschaften

Von: Armin Schäfer

Handke hat im Laufe seiner Werkbiographie verschiedene Fiktionen der Leserschaft ${ }^{1}$ errichtet. Die Fiktion eines Volks der Leser, die er in den 1980er Jahren entwirft, gerät nicht zuletzt durch die Figur des Fans in eine Krise: Der konkrete, einzelne Leser, der aus der anonymen Leserschaft heraustritt und den Dialog mit dem Autor sucht - und insbesondere die Leserin - ist jene Figur, die in den literarischen Texten als Bedrohung, Gefährdung des Autors erscheint und in inm unbeherrschbare Ängste und Phantasmen weckt. Die Unterstellung einer Leserschaft erfährt im Spätwerk eine Figuration, die auf einem idealisierten Modell beruht: Handke errichtet die Fiktion, dass der Leserschaft eine für sie konstitutive Autor-Hörer- bzw. Autor-Leser-Beziehung vorausliege. Der intradiegetische Leser präfiguriert nicht mehr den Fan, der lästig fällt, sondern einen ebenso anonymen wie individuierten Leser, der zwar eine Adresse hat, über gewisse Eigenschaften und Merkmale verfügt, aber kein Gesicht besitzt: sozusagen ein geheimer Zwilling des männlichen Lesers.

Der Kreis der idealen Leserschaft wird im Spätwerk enger gezogen und die Fiktion einer flüchtigen Gemeinschaft errichtet, die sich um einen Autor-Helden versammelt. Diese Fiktion produziert eine Unterstellung im Wortsinn: Die Leserschaft wird in ihrer Gesamtheit wie auch jeder einzelne Leser dem Autor untergeordnet. Der Autor erteilt zwar keine Befehle und übt auch keine unmittelbare Macht aus. Er lockt den Leser jedoch in eine Fiktion hinein, die ihm das Erzählen als die Vollendung eines der Lektüre vorausliegenden Abenteuers und das Lesen als dessen Abglanz hinstellt. Handke aktualisiert die als ursprünglich geltende Vermittlungsweise der oralen Dichtung für das 21. Jahrhundert und errichtet in der Fiktion eine Leserschaft, für die der Autor das Verbindungsstück und der Ursprung, das Medium und die Botschaft der Literatur ist.

Die Langfassung dieses Beitrages in der Reihe „Unterstellte Leseschaften“ finden Sie hier.

\section{References}

1. In den schönen Neologismus ,Leseschaft', den Moritz Baßler, Hanna Engelmeier und Andrea Geier geprägt haben, muss im folgenden Beitrag über Peter Handke leider der Buchstabe „r“ zurückkehren. Vgl. dazu die Langfassung. 
SUGGESTED CITATION: Schäfer, Armin: Abstract zu: Peter Handkes Fiktionen der Leserschaft, in: KWI-BLOG, [https://blog.kulturwissenschaften.de/abstract-zu-peterhandkes-fiktionen-der-leserschaft/], 24.05.2021

DOI: https://doi.org/10.37189/kwi-blog/20210524-0830

DuEPublico

Duisburg-Essen Publications online
DEU S'SE B U R G

offen im Denken

ub

universitäts bibliothek

Dieser Text wird via DuEPublico, dem Dokumenten- und Publikationsserver der Universität Duisburg-Essen, zur Verfügung gestellt. Die hier veröffentlichte Version der E-Publikation kann von einer eventuell ebenfalls veröffentlichten Verlagsversion abweichen.

DOI: $\quad 10.37189 /$ duepublico/74188

URN: urn:nbn:de:hbz:464-20210520-145644-4 